\title{
Grupos científicos e as forças políticas neoliberais que desmontam via terceirização a saúde pública no Brasil: primeiras notas
}

Ibrahim Rogério Jarochinski MARINHO: Faculdade de Saúde Pública - FSP, Universidade de São Paulo - USP. ORCID: https://orcid.org/0000-0002-4064-2054

Leonardo CARNUT: Universidade Federal de São Paulo - UNIFESP. ORCID: http://orcid.org/00000001-6415-6977

\section{Resumo}

O presente trabalho visa analisar de maneira crítica as dificuldades da gestão pública através de seus aspectos relacionados às políticas neoliberais que promovem a tentativa de capturar o setor público pelo setor privado através de grupos científicos aliados às forças políticas neoliberais. Pode-se notar que na atualidade um dos problemas mais significativos enfrentados pelo SUS são os embates quanto ao financiamento da saúde pública que são impostos pelas condições das políticas macroeconômicas adotadas, em especial neste período do capitalismo contemporâneo, implicando pressões diversas sobre os recursos financeiros da Seguridade Social e do Sistema Único de Saúde (SUS). Neste cenário, há um evidente jogo de forças políticas antagônicas que visam desmantelar a captação dos recursos seguros condizentes com as reais necessidades do sistema universal de saúde. Além disso, pode-se destacar um contraponto bastante considerável, onde visualiza-se um grande mercado de planos de saúde que passa a cobrir o polo dinâmico da economia, funcionando em antagonismo às diretrizes constitucionais do SUS que já enfrenta as fragilidades de suas redes regionalizadas e hierarquizadas, sobretudo quando se trata dos serviços municipais descentralizados. A partir da Emenda Constitucional-95, tem sido cada vez mais devastadora a transferência das responsabilidades para estados e municípios através do desfinanciamento do setor, reduzindo a capacidade de coordenação do sistema além da perda de efetividade, aumento de competição e da fragmentação dos serviços, acarretando o aumento da desigualdade de acesso aos serviços de saúde no país. Outro ponto a ser evidenciado, trata-se da efetiva humanização do sistema, que deve ser iniciada

Recebid o: 6 out. 2020 Aceito: 21 out. 2020

Autor de correspondência: Ibrahim Rogério Jarochinski Marinho

irjmarinho@gmail.com

Conflito de interesses:

Os autores declaram não haver nenhum interesse profissional ou pessoal que possa gerar conflito de interesses em relação a este manuscrito. através dos servidores em direção aos usuários, uma vez que não basta apenas responsabilizar os serviços que não estejam realmente estruturados, é necessária a busca constante de parcerias com os usuários para que através de mecanismos de controle social possa ser combatido o desmonte deste serviço de caráter universal. O SUS, enquanto política pública, tem a capacidade de contribuir para a constituição do sujeito, para a gestão e para as práticas profissionais, sendo capaz de modificar padrões de subjetividade promovendo importantes debates que passam a fortalecer a equidade no cuidado aos usuários, bem como promover a reflexão crítica no que tange os processos de gestão do trabalho e qualificação dos servidores. A história brasileira coloca nas mãos dos defensores sociais a necessidade da superação deste momento crítico, tornando-se imprescindível a construção de projetos apoiados de maneira integral pela sociedade, investindo no SUS universal não apenas em seu acesso, mas também em sua luta e sobretudo em sua defesa, abandonando definitivamente a forma neoliberal de pensar e fazer saúde pública. Assim, o objetivo deste estudo foi identificar os grupos científicos e suas relações com as frações de classe burguesa que simbolizam as forças políticas neoliberais que estão provocando o desmonte via terceirização da saúde pública no Brasil. Os objetivos específicos são: 1) Identificar os autores dos artigos científicos que analisam as forças políticas neoliberais que 
estão provocando a terceirização da saúde pública no Brasil; 2) Caracterizar os grupos científicos nos quais estes autores pertencem e suas relações sociais com governos e empresas assim como os financiamentos de pesquisa que recebem; 3 ) Analisar as possíveis relações de interesse destes grupos científicos com frações da burguesia interessada em terceiriza a saúde pública no Brasil. Trata-se de uma revisão integrativa, buscando bibliografias relevantes que tiveram como ponto de partida a seguinte pergunta: "Como as forças políticas neoliberais estão provocando o desmonte da saúde pública no Brasil?" O principal objetivo deste trabalho é contribuir para um maior entendimento do tema abordado, possibilitando uma melhor contribuição para discussões sobre métodos e resultados de pesquisas, mapeando e entendendo os espaços existentes na revisão pretendida. A respectiva pergunta permitiu selecionar palavras (termos-livres) a partir de suas relações com os itens-chave da pergunta. Foram utilizadas como termos-livres aqueles mais frequentemente usados pela plataforma do Sistemas de Bibliotecas FGV - Banco de dados Fundação Getúlio Vargas - FGV (https://sistema.bibliotecas.fgv.br) e foi neste banco de dados em que a busca foi realizada. Foram selecionados os cruzamentos que apresentaram resultados mais expressivos na tentativa de responder à pergunta de pesquisa. A sintaxe final escolhida que mais se adequa pergunta de pesquisa foi: TX ( "serviços terceirizados" OR "organizacoes sem fins lucrativos" OR "privatizacao" OR "organizacoes sociais" OR "OS" OR "OSS" OR "OSCIP" OR "terceiro setor" OR "reforma do Estado" OR "gerencialismo" OR "reforma gerencial" OR "terceirizacao" ) AND TX ( "neoliberalismo" OR "forças políticas" ) AND TX "sistema único de saúde". Até o momento chegou-se a 342 publicações identificadas.

Descritores: Serviços Terceirizados; Organizações sem Fins Lucrativos; Coalizão em Cuidados de Saúde; Saúde Pública; Setor Privado.

Keywords: Outsourced Services; Organizations, Nonprofit; Health Care Coalitions; Public Health; Private Sector.

Palabras-claves: Servicios Externos; Organizaciones sin Fines de Lucro; Federación para Atención de Salud; Salud Publica; Sector Privado. 